\title{
BUSINESS VALUE CREATION FROM IT INVESTMENTS: TOWARDS A PROCESS THEORY OF IT GOVERNANCE
}

\author{
Prof Peter Marshall \\ Assoc. Prof Judy McKay \\ Dr Adi Prananto \\ University of Tasmania \\ Swinburne University of Technology \\ Monash University \\ School of Information Systems \\ University of Tasmania \\ Hobart, Tasmania \\ Email: peter.marshall@utas.edu.au \\ School of Information Technology \\ Swinburne University of Technology \\ Hawthorn, Victoria \\ Email: jmckay@it.swin.edu.au \\ School of Information Management and Systems \\ Monash University \\ Caulfield, Victoria \\ Email: adi.prananto@sims.monash.edu.au
}

\begin{abstract}
The history of Information Systems (IS) as a discipline has been accompanied by vigorous debate on how, and indeed whether, IT investments contribute to improving organisational performance and hence in delivering value to the organisation. A number of models have been put forward to describe the relationship between IT expenditure and business value. This paper considers one such model, the process model of Soh and Markus (1995), and although this model has many attractive features, it is perhaps deficient in the way in which it links IT investment proposals back to business objectives, drivers and requirements. A modification of this model is thus proposed, and empirically assessed through qualitative interviews with CIOs in large organisations to understand the practises and processes by which they assert that business value is achieved through IT investments. The modified model was largely supported by the empirical study, but an additional factor, that of the need for and importance of sound IT governance processes and procedures to be in place if business value is to be derived form IT expenditure.
\end{abstract}

Keywords Process model, IT investment, IT governance, business value

\section{INTRODUCTION}

Despite the demise of the dot-coms and much of the over-heated enthusiasm of the "e-business revolution" and the consequent collapse in both spending on IT and confidence in IT (Coltman et al 2001), IT is still critically important in today's business world in terms of organisational efficiency and effectiveness and business competitiveness. Today's businesses could not survive, let alone compete without appropriately well designed and well implemented IT systems. Indeed IT now represents the fastest growing area of capital expenditure (Strassman 1997, Willcocks and Lester 1999), and in some large, IT-dependent organisations, capital expenditure on IT can exceed $50 \%$ of total capital expenditures (van der Zee 2002). However, the relationship between IT investments and firm performance is neither simple nor well understood. Indeed, as the experience with, for example, ERP systems shows, there is a lot more involved than buying a commodity product and plugging it in to the organisation. Bharadwaj (2000: 169), considering the link between IT investment and firm performance, writes "Despite the widely held belief that information technology 
(IT) is fundamental to a firm's survival and growth, scholars are still struggling to specify the underlying mechanisms linking IT to financial performance”.

Since the early days of IT, but certainly from the 1980s onward there was vigourous debate and research regarding how IT investments led to business value in the form of organisational efficiency and effectiveness and in the form of business competitiveness. The guiding theory of the firm used in these studies was the industrial economics view of the firm or the strategic positioning view (McFarlan 1984, Ives and Learmonth 1984, Porter and Miller 1985, Johnstone and Vitale, 1988, Feeny and Ives 1990). The upshot of a decade of work on this view was the conclusion that while you may achieve some cost efficiencies with IT, it was extremely difficult to improve organisational effectiveness, strategic positioning and business competitiveness via IT (Clemons and Row 1991, Kettinger et al 1994, Peppard and Ward 2004). There is, however, an emerging literature that utilises the resource -based view of the firm as a lens to examine the relationship between IT investment and corporate effectiveness and competitiveness (Soh and Markus 1995, Powell and Dent-Micallef 1997, Bharadwaj 2000, Sambamurthy et al 2003, Peppard and Ward 2004). This literature links firm performance to organisational resources and capabilities, one of which is IT capability (Bharadwaj 2000, Peppard \& Ward 2004). A critical part of IT capability is having the right business and management processes to be able to supply, deliver and exploit IT systems, or, perhaps better, solutions (Peppard and Ward 2004). Thus, a good strategy process and project processes are needed together with appropriately skilled and knowledgeable human resources.

IT investments will be successful in creating business value in terms of improved organisational effectiveness and business competitiveness, if the right IT investment is chosen in the first place, and then the right IT investment is linked to the right combination of process redesign, people skills and commitments and the like, and then the mix is well managed so that an effective organisational system emerges. Thus, even if a good IT strategy process selects the right IT investments, then, simply put, these IT investments alone will not create business value. IT investments are likely to create business value if, when linked to the right human and business resources, their realisation as a working system is managed well. Thus the way in which business value is created is still a focal area for concern among IT practitioners and practitioners alike. Indeed, it could be said to be the area of concern in the field of Information Systems! Given these concerns, the study reported in this paper explored how senior IT executives in large private organisations went about creating the conditions under which business value was harvested from IT investments. A framework of structures and processes emerged that is reported later in the paper. We would argue that it is this framework that, broadly speaking, sets the conditions for the realisation of value from IT investments.

\section{DERIVING BUSINESS VALUE FROM IT}

As discussed above, over the years there has been considerable debate over the extent of IT's contribution to business value, and indeed, whether or not organisations have derived adequate or reasonable value from their IT expenditure (Farbey et al. 1999, Kohli and Devaraj 2004). At the heart of much of this debate are the associated issues of effectively establishing quality measures of value that are reliable, and hence credible to senior executives (Kohli and Devaraj 2004), and that of understanding the processes by which business value is created through expenditure on IT (see Weill 1992, Soh and Markus 1995, for example). The research reported in this paper was oriented towards this second issue, that of understanding the processes by which executives in organisations believe they accrue value from their IT investments.

In a seminal paper, Earl (1990) argued that expenditure on IT on its own would not lead to improvements in business performance, asserting that there was little evidence of IT expenditure on its own directly resulting in improved business performance or outcomes. Furthermore, Earl (1990) 
claimed that greater sophistication in understanding the relationship between business value and IT expenditure was required, and that conceptualising IT investment as being accompanied by other required business changes was not sufficient to account for the contribution of IT to improved business performance. His suggestion was that IT expenditures would only have the desired effects when they resulted from business-led analysis and identification of opportunities and requirements, followed by appropriate IT investments and acquisition of required IT capabilities. Subsequent to Earl's (1990) paper, a number of theoretical models appeared focused around addressing such issues during the 1990s (see Lucas 1993, Grabowski and Lee 1993, for example). Soh and Markus (1995) considered the features of each of these models and frameworks, from which they synthesized a process model to explain how IT creates business value. Their model (see Figure 1 below) outlines the necessary chain of events if the desired outcome of delivering business value is to be accomplished.

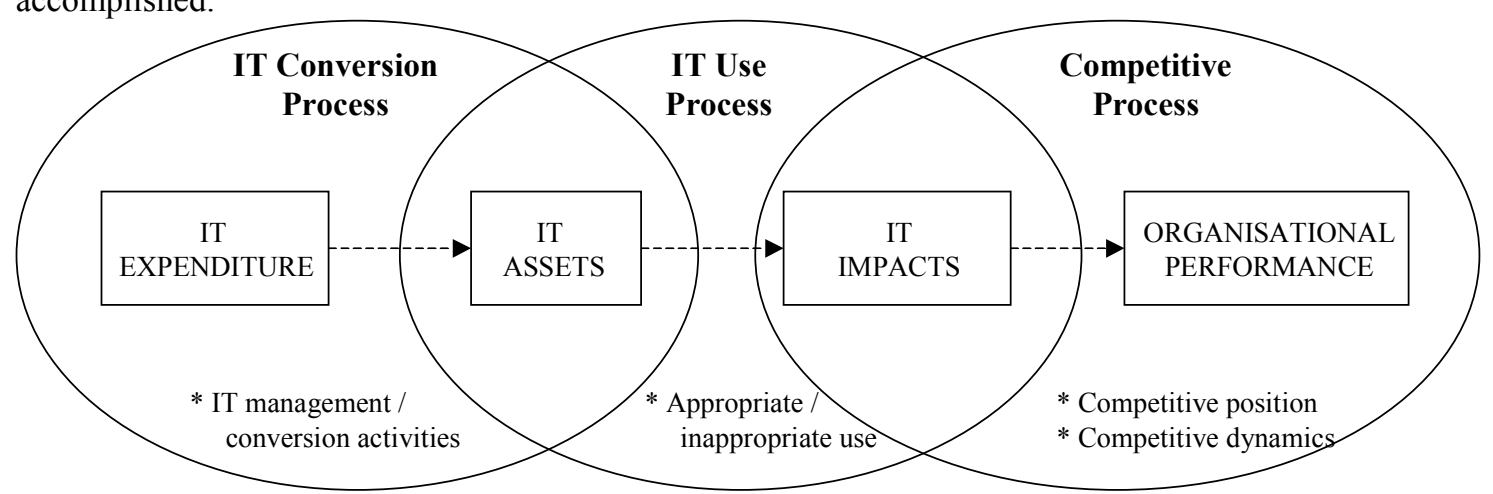

Figure 1: A Process Model for the Creation of Business Value from IT (Soh and Markus 1995)

The gist of the argument underpinning this model can be succinctly articulated as follows. Soh and Markus (1995) see business value and an expected positive contribution to business performance derived through three linked processes: the IT conversion process, the IT use process, and the competitive process. IT assets are created through converting expenditure on IT into artefacts regarded as assets of the organisation. Effectively converting money and other resources into an asset for the organisation is contingent upon a number of IT management activities. IT assets, however, will only have the desired impact in an organisation if they are used appropriately and benefits from these investments are proactively managed. Ensuring appropriate IT use in given contexts thus becomes the means by which IT assets create the desired IT impacts on the organisation. Appropriate redesign of business processes together with the appropriate restructuring of roles and responsibilities to ensure good organisational fit for the information system are important factors in this regard. However, whether or not IT impacts have the desired effect on organisational performance is contingent on a number of factors, many of which are outside the control of the organisation. For example, the nature of competition in the industry, the behaviour of competitors, the general state of the economy, and so on, will all impact on organisational performance. Thus, improvements to organisational performance through the impacts of IT may result only when general business conditions are favourable (Soh and Markus 1995).

There are a number of attractive features about this model. Firstly, conceptualising the creation of business value from IT as a process helps to underscore the on-going and dynamic nature of this transformation, and indeed, indicates that several levels of uncertainty exist in realising value form IT. For example, if IT expenditure relies on sound management practices for it to be converted into an IT asset, then in all organisations there will be variability and some uncertainty as to how 
effectively and consistently this can be accomplished. Similar uncertainties and issues are evident at each stage of the Soh and Markus (1995) process. Secondly, it clearly illustrates that responsibilities for deriving value from IT investments lies well beyond the bounds of the IT staff, thus helping to avoid the issue alluded to by Peppard et al. (2000) who note that when IT 'disappoints', and there is uncertainty amongst management as to its benefits and value to the organisation, the dominant perspective in the literature attributes these shortcomings to the IT function. The Soh and Markus model encourages an organisationally-based view and understanding of responsibilities in this process.

Of concern, however, is the starting point of this model as "IT Expenditure" with the concomitant concern that this might encourage a regression in thinking back to the notion that IT expenditure will give rise to business benefits. Admittedly, Soh and Markus (1995) acknowledge that IT expenditure embraces IT managerial activities including IT strategy formulation, designing IT structures, selecting and managing IT projects. However, somewhat absent from their discussion is the linkage back to business strategy and business requirement. In our view, the model is thus deficient in that it fails to take account of Earl's (1990) claim that a business-led approach to IT expenditure is required, with business opportunity and need driving decisions on IT investments. This position is effectively supported by the recent work of Kohli and Deveraj (2004). Thus, we would argue for a modification to the model, to ensure that the business focus of IT expenditure is both explicitly recognised and featured in the model, and accorded the focus and prominence it requires and deserves (see Figure 2 below).

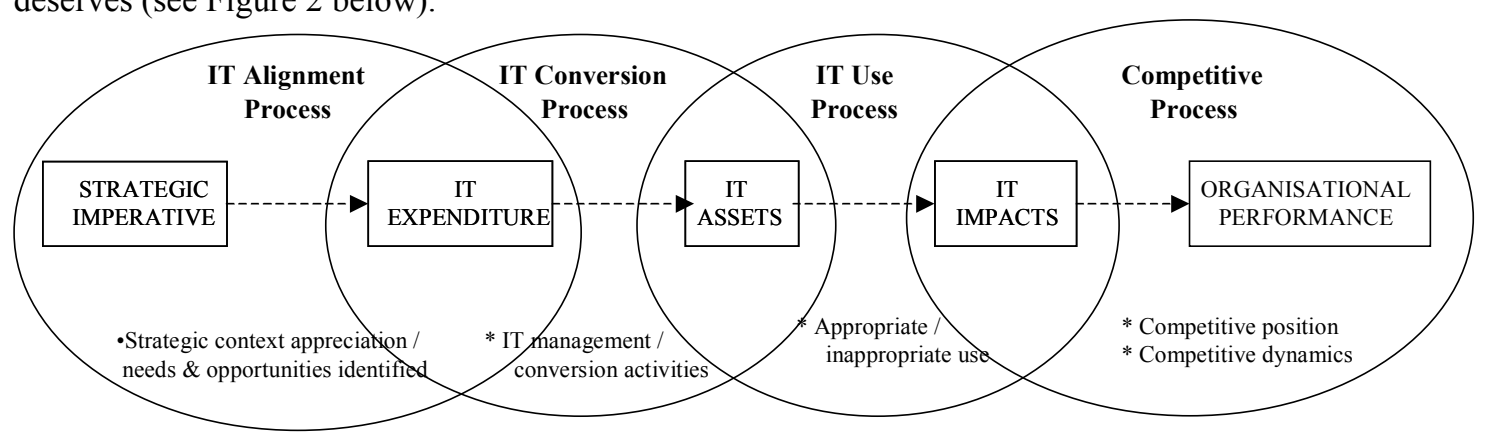

Figure 2 A Modified Process Model for the Realisation of Business Value from IT

In addition, the authors argue that this modified process model offers another attractive feature: in essence, it 'closes the loop' between organisational performance and business strategic thinking, resulting in a need for IT expenditure. It is our contention that the strategic imperative of the organisation, appreciating business opportunities and needs, and making sound IT investment decisions in order to support and enable these business opportunities and needs all arise as a result of a perception that business performance can be, or needs to be, improved. It thus serves to cement the processes of expending money and driving value from IT not just subsequently to the desire to improve organisational performance, but also to business-based drivers, opportunities and strategic initiatives.

Key activities in this additional first stage then would include understanding the strategic, or competitive environment of the organisation, and the threats and opportunities inherent in such environments. It would involve identifying both business and technology opportunities, and in articulating a coherent investment strategy for IT which would result in IT investments clearly and overtly aligned to the business strategy and direction of the organisation. Thus, achieving a strategic 'fit' between an organisation, its objectives and strategies, and its IT investment strategy and 
portfolio would be a key concern here. So too would ensuring that the development of required IT capabilities over time was appropriate for the business. IT initiatives may also come from perceptions of needs and wants from business executives, but another activity at this stage would be to match these perceptions of want to business initiatives once again to ensure alignment and to facilitate prioritisation, via the formulation of a compelling and increasingly detailed and persuasive business case.

The case for the modification of the Soh and Markus model is one based on the clarity, accuracy and authenticity given to the description of the IT business value creation process by splitting the stage of IT Expenditure to IT Assets into two stages, the first of which is Strategic Imperative to IT Expenditure, and the second of which is the first stage in the previous model, visually IT Expenditure to IT Assets. We felt that our description of the business IT value creation process would be improved and clarified by having this extra stage, or at least, by making this first stage explicit and distinct. Some indication of the need for this extra focus on the analysis of strategic imperatives and what they imply in IT terms will become apparent as readers assess the description of our research findings. It will become clear that this first stage is highly significant and important to the creation of IT business value.

\section{RESEARCH METHOD AND DESIGN}

As indicated in the previous section, the research sought to explore the issue of the creation of business value from IT, in particular, the key processes, activities and practices by which senior executives believed their organisation ensured the achievement of benefit and value from IT expenditure. We were thus addressing the question: how did senior executives ensure that IT investments resulted in subsequent increases in organizational efficiency and effectiveness, and/or business competitiveness. We believed that the best sources of knowledge on IT business value and the clearest insights would come from the large private companies with large IT spends, long histories of applying IT to business and hence possessing IT maturity and sophistication, and a reputation for being leaders in the effective and possibly innovative management of IT.

Organisations with the above characteristics were approached and the Chief Information Officer (CIO) was asked to make available up to two hours for an in-depth interview on IT strategy and management in their organisations, with particular emphasis on their perceptions of how IT value could best be derived. The CIOs of a number of such organisations agreed to take part in the study. The organisations that they represented either were among the largest private businesses in Australia, or were the Asia-Pacific headquarters of huge global businesses with a substantial presence in Australia and the Asia-Pacific. The interviews took between one and two and a half hours. Relevant company documents were also provided to and read by the researchers.

The interviews were recorded, transcribed and then subjected to qualitative content analysis. The researchers searched for themes, issues and practices that shed light on the derivation of business value from IT. A number of common themes, issues and practices began to emerge from the research data. The interviews were continued with new organisations until a stable pattern of findings began to emerge, and few new insights began to occur. By this time, eleven organisations had been considered. Basic data on these eleven organisations is shown in Table 1. 


\begin{tabular}{|l|l|l|l|l|l|}
\hline Company & Industry & $\begin{array}{l}\text { IT } \\
\text { Operating } \\
\text { Budget }\end{array}$ & $\begin{array}{l}\text { IT Capital } \\
\text { expenditure }\end{array}$ & $\begin{array}{l}\text { IT as \% of } \\
\text { capital } \\
\text { expenditure }\end{array}$ & $\begin{array}{l}\text { Years as } \\
\text { CIO }\end{array}$ \\
\hline A & Retail & $\$ 100 \mathrm{~m}$ & $\$ 80-100 \mathrm{~m}$ & $12 \%$ & 3 \\
\hline B & Pharmaceuticals & $\$ 4 \mathrm{~m}$ & $\$ 4 \mathrm{~m}$ & $5 \%$ & 12 \\
\hline C & Manufacturing & $\$ 35 \mathrm{~m}$ & $\$ 7 \mathrm{~m}$ & $7 \%$ & 6 \\
\hline D & Financial Services & $\$ 55 \mathrm{~m}$ & $\$ 48$ & $60 \%$ & 4 \\
\hline E & Leisure/Entertainment & $\$ 50 \mathrm{~m}$ & $\$ 15 \mathrm{~m}$ & $30 \%$ & 5 \\
\hline F & Food \& Beverage & $\$ 52 \mathrm{~m}$ & $\$ 10 \mathrm{~m}$ & - & 3 \\
\hline G & Financial Services & $\$ 500 \mathrm{~m}$ & $\$ 400 \mathrm{~m}$ & $70 \%$ & 3 \\
\hline H & Financial Services & $\$ 400 \mathrm{~m}$ & $\$ 250 \mathrm{~m}$ & $60 \%$ & 5 \\
\hline I & Financial Services & $\$ 42 \mathrm{~m}$ & $\$ 35 \mathrm{~m}$ & $55 \%$ & 3 \\
\hline J & Food \& Beverage & $\$ 28 \mathrm{~m}$ & $\$ 74 *$ & $7-8 \%$ & 1 \\
\hline K & Manufacturing & $\$ 58 \mathrm{~m}$ & $\$ 35 \mathrm{~m}$ & $3 \%$ & 1 \\
\hline
\end{tabular}

(Note: All figures cited are expressed in A\$, and for global companies, are for IT expenditures just in Australia)

* \$66m of this was a one-of ERP acquisition and implementation

Table 1: Company Demographics

The broad research objectives which shaped the interviews were motivated by the modified Soh and Markus (1995) model (see Figure 2), and can be articulated as follows:

- To understand the notion of business value from an organisational perspective;

- To 'test' the proposed modifications to the Soh and Markus (1995) model, and thus to see whether there is adequate empirical evidence to support the additional 'stage' of strategic imperative, as outlined in previous sections.

\section{RESEARCH FINDINGS}

\section{The notion of business value}

All CIOs interviewed were very clear when it came to business value: ultimately, they saw business value from IT as contributing ultimately to increased profitability. Most reported that this was an integral part of the transformation their organisation had been through with respect to IT: that their organisations had, in the past few years, moved quite dramatically away from an obsession about costs (IT was viewed principally as a way of driving down costs) to a focus on value. IT was seen and managed as a way of adding value to the organisation, either through reducing costs, or by increasing efficiency, or by increasing effectiveness in the form of valued service from a range of perspectives (customers, suppliers, alliances, etc.), through IT-enablement of core business processes, or through increasing flexibility and responsiveness, or by taking advantage of new opportunities. 
D: Well, ultimately, it comes back to improving your profit - getting your unit costs down or improving your customer and advisor satisfaction, and that often comes from better business processes.

F: I have to be able to show that the benefits derived from an investment generates sufficient value over and above the original investment over a period of time...the Board insists on that... We don't worry so much about costs now - well, within reason -

\section{Support for the modifications to the Soh and Markus (1995) model}

Tables 2, 3, and 4 below summarise the organisational activities and practices according to the modified Soh and Markus (1995) model. In the eleven organisations in our study, these were identified form the transcripts as the practices contributing to the delivery of business value. Not every one of these was present in each organisation, but a substantial subset would have been, and some CIOs flagged particular practices as ones that they did not do, or did not do well, but which they regarded as important.

From Strategic Imperative to IT Expenditure

\begin{tabular}{|l|l|}
\hline Phase & Practices \\
\hline $\begin{array}{l}\text { Strategic Imperative } \\
\text { to IT Expenditure }\end{array}$ & Formulating IT vision and strategy \\
\hline & Aligning and embedding IT strategy in business strategy \\
\hline & Identifying IT opportunities \\
\hline & Prioritizing and selecting IT investment proposals \\
\hline & $\begin{array}{l}\text { Building a broad but rigorous business case for IT investment opportunities, including } \\
\text { evaluating proposals and identifying business benefits, and estimating the time } \\
\text { required to realise benefits }\end{array}$ \\
\hline & Identifying IT investment project risks \\
\hline & Constantly monitoring and reassessing proposals for organisational and strategic fit \\
\hline
\end{tabular}

Table 2: From Strategic Imperative to IT Expenditure

Our interviews would tend to suggest that this was the most emphasised, the most mentioned, and perceived to be the most critical phase in the ultimate achievement of business value from IT. All the CIOs in our study emphasised the requirement to carefully articulate a vision and high-level strategy for IT, which then served as an overarching framework for all proposed IT investments. The IT vision and strategy was generally articulated by a combination of IT and senior business executives, with the determination that IT should be aligned with, and thus support the achievement of business visions, goals, and objectives. The need for alignment, for vigilance in maintaining alignment, and in embedding IT thinking and strategising in business need and opportunity was a repeated theme in our conversations with executives. This was seen as an on-going, 'incessant' activity, and one viewed as being essential to the ultimate delivery of business value

E: $\quad$ I have spent my first eight months on three things. Alignment, both to the business strategy and the global IS standards, engagement both with the business to understand the business strategy and the global IS business if you like. Governance which is about getting a process by which you can prioritise and manage and it was the third thing that I did, and then financial control. So those are the four things I've been doing and none of them have the word 'IT' in them. But it's managing information systems, not 'OK, which technology do I buy this week?" that people don't understand. Actually the technology decision is really easy if you get the bit at the top right. 
K: the picture I've got is there's an umbrella across the top that talks about the business strategy and the IS strategy or the IT strategic plan for the company. Then underneath that there are IS plans for each part of the business. So what you've got is kind of like an umbrella that says we have an overall strategy. Each of the business units have key IS plans which are integrated to any business process change they are trying to do or any change in their business and then underneath that I have to have a layer which integrates all of those plans to an architecture.

B: $\quad$ Our investments today are targeted to support our strategic imperatives - so if the strategic imperatives are right then they're the things that count ... we've got to check the allocation to [IT] investments is consistent with our strategy which is consistent with our strategic imperatives

K: $\quad$...regarding the business case and where IT project ideas come from - we should back up a bit and have to maybe talk for a minute about the governance structure first. What we have is both a top down and bottom up governance structure. So we have a business strategic plan for [company name] and we have business unit plans that link to the strategy, you know, strategic plan of the business. And then we have you have an IS strategy which links to and supports the business strategy and then you have an IS plan in each business unit which supports the business plan. So what happens then is that you must link

The CIOs all believed that an important component of delivering value was to identify IT opportunities. Opportunities for IT investments emerged from business needs or desires, or to avoid strategic disadvantage (i.e. in response to innovation by their competitors), but whatever the driver, CIOs agreed on the need for a compelling business case to be articulated before any IT investment would be contemplated. The business case included consideration of likely costs and possible benefits from proposed IT investments, and was revisited on a number of occasions, each iteration resulting in greater certainty as to costs and feasibility, increased confidence in the organisation's ability to achieve the benefits, greater surety in the time both to acquire and to reap benefits from the proposed investment, and certainty as to the fact that the investment proposal involved the building of required and useful IT capabilities. Evaluation at this stage also emphasised the need to identify IT-related risk, and to put in place a plan to manage exposure from the proposed investment. Activities at this stage were fluid, with constant worrying and checking that proposed IT investments were still aligned with business directions, that they represented a good strategic fit, and that there was clear understandings between business units and IT on the nature of the requirements, expectations, and the like. All the CIOs interviewed reported formal IS/IT planning processes and mechanisms, with plans and strategies subject to more frequent reviews (3-6 monthly), where business goals, objectives, and priorities were re-evaluated, and then IS/IT initiatives re-evaluated in the light of possibly changing business initiatives. It was during this process that new proposals for IS/IT investments were considered, with very careful scrutiny of each proposal being conducted to ensure that any resultant IT investment would be aligned and consistent with strategic business imperatives.

H: Somebody will come up with an idea in a business unit which is the way it works. That needs to be the first thing that happens because the planning managers are linked to me, and a single strategic planning group, and idea comes inside my group and we talk about whether it's really a business unit idea or it's an enterprise idea. We would then create a program manager sponsored by myself because I take the cross business projects, because I'm on the board it's quite easy to do. You just sit at the board table and agree that we're going to do this enterprise wide and then that program manager will work with the planning managers to develop the business case for the enterprise. The business 
justification and the benefits and the project itself must go up through each business unit's IT steering committee because each business unit must commit to the program and must to commit to their part of the benefits

E: $\quad$ So we've got a very strict business case preparation and authorization process that has as its basis the calculation of the return on the investment over an accepted period of time...I don't even accept productivity gains anymore. If someone tries to present a business case based on productivity gains then I want names of the people that aren't going to be working here anymore, what their salaries are, and what day they're going to be leaving...

From IT Expenditure to IT Assets

\begin{tabular}{|l|l|}
\hline Phase & Practices \\
\hline IT Expenditure to Assets & Managing IT project risk \\
\hline & $\begin{array}{l}\text { Redesign of business processes, and assessing and planning required } \\
\text { business change }\end{array}$ \\
\hline & $\begin{array}{l}\text { Preparing a detailed business case including the evaluation of } \\
\text { specific costs and benefits }\end{array}$ \\
\hline & $\begin{array}{l}\text { Project management - effectively managing all aspects associated } \\
\text { with acquiring and/or developing the desired information system }\end{array}$ \\
\hline & $\begin{array}{l}\text { Carry out evaluations of the partly developed system or proposed } \\
\text { system including checks on changing business requirements }\end{array}$ \\
\hline
\end{tabular}

Table 3: From IT Expenditure to IT Assets

When a decision had been made to proceed with a particular investment proposal, then the focus of activities changed somewhat, and a greater concentration on the project itself became evident. CIOs reported an increased focus on project management issues, with great emphasis now placed on adequately identifying and managing IT project risk. Changes to the system were in some cases paid careful attention, with an emphasis by some CIOs in ensuring that project changes did not compromise the ability to achieve benefits form the IT investment. In addition, most organisations seemed to be more keenly aware of the need to carefully look at the business processes supported by IT or embedded in newly purchased software, and to consider carefully the issues of business process reengineering (BPR) to accommodate some of the business changes initiated by the new IT investment. Most CIOs seemed very sympathetic to the position that implementing new IT systems without revisiting the business processes underpinning these systems would be unlikely to result in the best value being derived by the organisation.

Throughout the project, analysis typically continued into both the costs and benefits of the IT project. Business cases were still subject to revision and confirmation, with regular reviews conducted to oversee the management or containment of costs, and the certainty associated with the delivery of benefits. In addition, these reviews included a revisiting of business goals and objectives, to ensure that projects were still tightly aligned with business directions. It was reported in a $\mathrm{n}$ umber of organisations that projects could and would still be cancelled at this stage (part way through development/acquisition) if there was any suggestion that business priorities had changed rendering the objectives of the IT investment less useful than anticipated.

$C$ : We have a gating process where people get their money to get through the gates to do the project ... that is the project is rigorously evaluated at each gate. So we have gate 0 to gate 1 which is really straight analysis - and there will be an IT business solutions manager involved in that - gate 1 to gate 2 is really high level analysis - not so much high 
level but it's the step 1 analysis and so on - gate 2 to gate 3 is detailed analysis and so on which just takes that a bit further - and then once you get to gate 3 - test, implement-at 4 - the project finishing is after such and such a period - that's the project finished - so we are continually analyzing, evaluating and re-evaluating - you know checking on progress, spend, relevance and so on, trying to intelligently react to changes

$H$ : but we have pulled some IT projects here and there, but if it's only going to be a bit late and it's running over a bit, well with some care of course, we might cut the scope back ...

\section{IT Assets to IT Impacts}

\begin{tabular}{|l|l|}
\hline Phase & Pppppppppp Practices \\
\hline IT Assets to IT Impacts & Post implementation reviews \\
\hline & Implementation of business process change \\
\hline & $\begin{array}{l}\text { Measurement of the achievement of goals and objectives for IT } \\
\text { investments }\end{array}$ \\
\hline & $\begin{array}{l}\text { Possible reallocation and restructuring of roles and responsibilities to } \\
\text { achieve organisational fit }\end{array}$ \\
\hline & Management of the realisation of benefits from IT investments \\
\hline & Evaluation of stakeholder satisfaction with IT \\
\hline & Assessment of perceived value of IT investments \\
\hline & $\begin{array}{l}\text { Management of business change required to accommodate IT } \\
\text { implementation }\end{array}$ \\
\hline & Training and reskilling \\
\hline
\end{tabular}

Table 4: From IT Assets to IT Impacts

One of the most common practices reported in ensuring that IT investments had the desired impacts was to conduct post implementation reviews (PIRs) for all projects. This involved typical project measures of whether the system was delivered on time, to budget, with the specified and required level of quality. However, some of the CIOs were aware that PIRs did not necessarily contribute much to the delivery of business value. These CIOs were all implementing proactive benefits realisation processes, whereby post project, serious efforts were made to assess and measure the effects and impacts of the system implementation, and to check whether the anticipated benefits were being realised. PIRs were argued to contribute to value from the perspective of enabling learning to take place about the effective management of projects. The intention of the benefits realisation or management processes evident in a few organisations however, were much more oriented towards ensuring that goals and objectives established pre-project for the IT expenditure had or were, in fact, being achieved. Thus these benefits-oriented types of evaluation tended to assess the IT investment more holistically in its business context, and thus also considered the effects and impacts of business process change and other associated business changes that had been necessitated by the implementation of the new system.

Not only were the impacts of these process and business changes assessed, but the interview data also suggests that there was recognition of the need to change jobs, roles and responsibilities in line with the IT investment, with the possibility acknowledged of a need for restructuring of the workforce and conditions. Thus, it was not uncommon for CIOs in this study to comment on the vital element of reallocating and restructuring roles and responsibilities, with the concomitant need for training and reskilling in light of the changes and impacts of the IT investment. For IT to have the desired impact, such changes were deemed absolutely essential. 
It was relatively common in organisations in this study for post-implementation reviews to be conducted of stakeholder satisfaction. The logic typically driving these initiatives was that stakeholders that are satisfied are more likely to make better use of IT investments, and hence the organisation is more likely to derive the business value and benefits identified pre-investment. However, some of our CIOs did acknowledge that stakeholder satisfaction was not always nor necessarily the same as deriving business value, but nonetheless, such surveys were generally regarded as useful indicators in many circumstances.

J: $\quad$ Yeah, we generally do post-implementation evaluation...not on time and budget issues. Oh no, it's more like "Did we achieve the business benefits and things like that?" It's on the positive side... and the achievement of benefits, or otherwise. Um, it'll be the IT people who pull together the review, but clearly it will need to draw on information and input from people right throughout the business

\section{DISCUSSION}

The modified Soh and Markus model, we believe is a valuable organising and sense making framework for describing and explaining the activities and processes involved in the effective realisation of business value from IT investments. The importance and emphasis placed on the first stage of IT strategy, IT opportunity identification, and IT-business analysis by the CIOs in our sample, we feel, justifies the explicit inclusion of the stage of Strategic Imperative to IT Expenditure. Of all the phases represented in the modified Soh and Markus (1995) model, the importance of closely linking IT initiatives to business drivers and requirements was regularly emphasised, and arguably was considered perhaps the most important element in ultimately deriving business value. We thus assert that there is empirical support for the modifications made to the model, and that the modified model (see Figure 2) better represents the concerns and practices of CIOs, at least in our sample of organisations.

It is of interest that we had few difficulties in identifying comments form he CIOs which supported this first phase, but that expressed support for the latter phase of moving from IT assets to IT impacts was less emphasised. For example, all CIOs talked a lot about issues of alignment, understanding the business imperatives, ensuring a business orientation to IT investments. The CIOs, when prompted, all talked about issues and practices associated with the move form IT assets to IT impacts, but some did need to be prompted, and there was less explicit recognition that appropriate system usage and ensuring the derivation of expected benefits were regarded as an integral part of their responsibilities in efforts to achieve business benefits from IT spend. In fact, while many of the CIOs interviewed recognised the requirement to assess the delivery of business benefits, this was the area where there was most divergence in the organisations in our study. Only two of the eleven organisations reported formal, rigorous benefits realisation programmes, where serious attempts were made to measure benefits achieved over time. These two organisations linked expected benefits to performance measures of project sponsors and Business Unit budgets. So, for example, if a proposed system was claimed to be able to reduce operating costs in a particular business unit by $5 \%$ per annum, the operating budgets for that unit would be cut by $5 \%$ the following year, and the manager of that business unit would have his/her performance measures and rewards linked directly to the achievement of that $5 \%$ reduction.

H: $\quad$ So they say to me, "David, we've got this fantastic system for our business, it's going to reduce costs by $2 \%$ if you give me that system". I say "Go ahead, but I'm taking $2 \%$ out of your budget for next year." And the same thing on the revenue side, that would add to your budget. They've got to get it...it makes the investment proposals much more realistic and cautious...serious. 
Most other organisations recognised that this was an area where they needed to improve, and many stated that it was on their agendas as a "to do" item, conceding that this was an important area where they needed to improve. However, some of the managers were concerned about the resources required to undertake such a benefits realisation process.

A: We certainly do a post implementation review of all our projects but if the question is more around benefits, do we go back rigorously a year later or whatever and say 'okay compared to what we predicted how did we do?' I've got to say we haven't been strong on that as I think we should've been but the other factor of course is that there's always a lot changing in the business anyway, so it's very hard to attribute an improvement to one specific project...it tends to be look we think we've got $80 \%$ of the benefits from what we've already done - rather than put a whole heap of extra effort into chasing proportionately less benefits, let's stop, and accept that there is some weaknesses in what we've done but there are bigger opportunities elsewhere

The issue being grappled with here is that as CIOs, they felt torn between the potential to derive greater benefits from the existing investments, as opposed to diverting resources to exploiting other IT opportunities. Interestingly, most of the CIOs still tended to adopt the satisficing position (i.e. that delivering, say $80 \%$ of expected benefits was probably good enough and that the resources consumed in trying to achieve $100 \%$ or more would be better diverted elsewhere). The CIOs in this study were aware of proactive benefits realisation, and that looking to enabling business changes and activities could help achieve business benefits. However many CIOs admitted that this aspect was not well established, and that they had not established an effective process of benefits realisation as part of the accepted routines of the organisation.

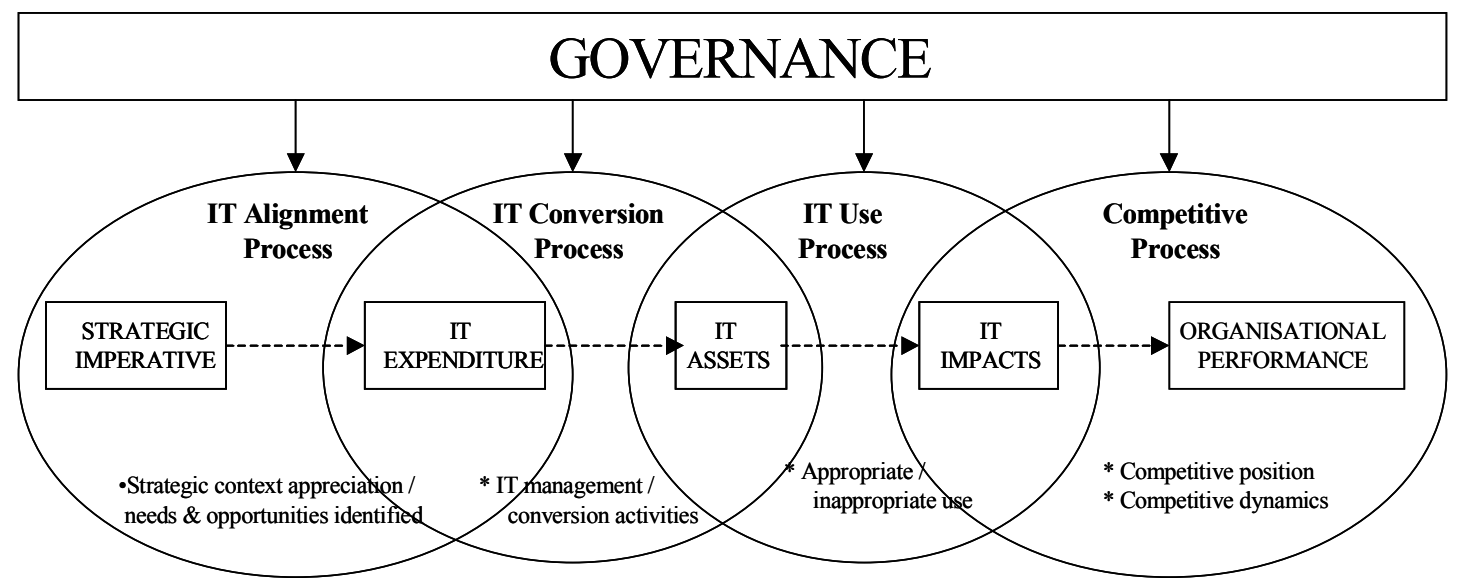

Figure 3: IT Governance and the Creation of Business Value from IT

What did emerge clearly from the interviews however, was the CIOs emphasis on issues of governance (see Figure 3 above). Previous quotes cited in this paper are testimony to this. In the minds of our CIOs, governance seems to involve a range of interconnected and overlapping elements. In the organisations studied, it appeared that governance was a function of articulating a vision and principles about the role and potential contribution of IT in a particular organisation. This was coupled with clear structures by which decision making accountabilities and responsibilities were formally identified. Principles and decision making structures, however, needed to be implemented via clearly articulated processes over time. But in addition, there was a concern, almost an obsession with many of our CIOs with building organisation wide IT capabilities 
and relationships, and adapting these over time, in order that appropriate systems and services could be delivered to the organisation, creating appropriate business value (see Figure 4 below).

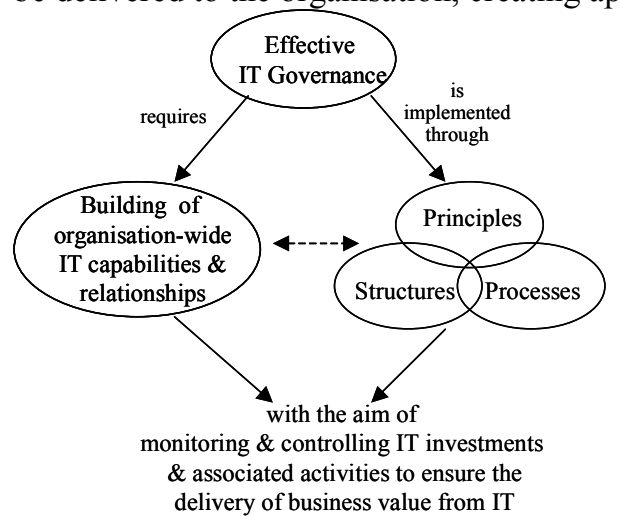

Figure 4: The Elements of IT Governance

Thus, it is our contention that good IT governance processes accomplish at least three broad objectives: they support an environment for the development, exercise and exploitation of IT resources and capabilities; they provide a framework for the fruitful exploration and explication of relationships between the IT function and the rest of the organisation; and they formally define, identify and underpin a series of organisational routines and procedures through which the business value of IT is realised and IT risk contained. The processes and activities to ensure IT business value will occur effectively, we believe, if they are formally defined and established by the organisation's IT governance framework. IT governance, we would argue, is a management framework consisting of the necessary structures and processes for the effective stewardship and management of business initiatives involving IT, from the identification of IT systems as part of business initiatives, right through to the realisation of benefits from implemented systems working in harmony with both people and business processes. Such a framework shapes and determines the nature of the IT business value creating processes, and we would argue, is necessary for effective and reliable business IT value creation

\section{CONCLUSION}

We have modified the Soh and Markus model by adding a first stage which concerned the activities of strategy formulation, IT opportunity identification and IT business analysis. This stage, in our view, was of critical importance to realising business value from IT investments. This stage was also viewed as critically important by the CIOs we interviewed, as evidenced by their focus on the role of these activities in realising IT business value. Thus we believe we have justified the inclusion of the stage as an explicit and separate part of the model. We hope that our extended model will prove useful in helping practitioners visualise and organise the process of obtaining business value from IT investments.

We have also taken the view that the establishment of an appropriate IT governance framework is critical to IT business value creation. We can view the knowledge of how to perform IT strategy formulation and IT project management and IT risk management activities and processes effectively as an internal resource that is critical to the task of extracting business value from IT investments. Such knowledge is partly tacit, but the more a firm can develop, grow and maintain such knowledge, and further, the more it can ensure such knowledge is shared among its employees, within the IT 
function and beyond, the more likely it is to profit from its IT investments.

\section{REFERENCES}

Bharadwaj, A. S. (2000) A Resource-Based Perspective on Information Technology Capability and Firm Performance: An Empirical Investigation. MIS Quarterly, Volume 24, No. 1, March, pages $169-196$.

Coltman, T., Devinney, T. M., Latukefu, A, and Midgley, D. F. (2001) E-Business: Revolution, Evolution or Hype? California Management Review, Volume 44, No. 1, Fall, pages 57-86.

Earl, M. J. (1990). Putting IT in its place: A polemic for the nineties (Oxford Institute of Information Management, Research, and Discussion Papers, RPD90/2). Oxford, England: Templeton College, University of Oxford.

Farbey, B., Land, F. and Targett, D. (1999) Moving IS evaluation forward: learning themes and research issues. Journal of Strategic Information Systems 8(1999): 189-207.

Feeny, D. F. and Ives, B. (1990) In Search of Sustainability: Reaping Long-Term Advantage from Investments in Information Technology. Journal of Management Information Systems, Volume 7, No. 1, Summer, pages 27-32.

Grabowski, M. and Lee, S. (1993) Linking information systems portfolios and organizational strategy. In R.D. Banker, R.J. Kauffman and M.A. Mahmood (eds.) Strategic Information Technology Management: Perspectives on Organizational Growth and Competitive Advantage, pp33-54. Idea Publishing Group, Harrisburg.

Ives, B. and Learmonth, G. P. (1984) The Information System as a Competitive Weapon. Communications of the ACM, Volume 27, No. 12, December, pages 1193-1201.

Johnstone, H. R. and Vitale, M. R. (1988) Creating Competitive Advantage With Interorganisational Information Systems. MIS Quarterly, Volume 12, No.2, June, pages 153-165.

Kohli, R. and Deveraj, S. (2004) Realizing the business value of information technology investments: an organizational process. MIS Quarterly Executive, 3(1): 53-68.

Lucas, H.C. (1993) The business value from information technology: a historical perspective and thoughts for future research. In R.D. Banker, R.J. Kauffman and M.A. Mahmood (eds.) Strategic Information Technology Management: Perspectives on Organizational Growth and Competitive Advantage, pp359-374. Idea Publishing Group, Harrisburg

McFarlan, F. W. (1984) Information Technology Changes the Way You Compete. Harvard Business Review, Volume 62, No. 3, May/June, pages 98-103.

Peppard, J. and Ward, J. (2004) Beyond strategic information systems: towards an IS capability. Journal of Strategic Information Systems, 13(2004): 167-194.

Peppard, J., Lambert, R., and Edwards, C. (2000) Whose job is it anyway?: organizational information competencies for value creation. Information Systems Journal, 10(4), 291322.

Porter, M. E. and Miller, V. E. (1985) How Information Gives You Competitive Advantage. Harvard Business Review, Volume 63, No. 4, July/August, pages 149-160.

Powell, T. C. and Dent-Micallef, A. (1995) Information Technology as Competitive Advantage: The Role of Human, Business, and Technology Resources. Strategic Management Journal, Volume 18, No. 5, pages 375-405.

Soh, C. and Markus, M.L. (1995) How IT creates business value: a process theory synthesis. In Ariav, G. et al. (eds.) Proceedings of the $16^{\text {th }}$ International Conference on Information Systems, December 10-13, Amsterdam, Netherlands.

Strassmann, P.A. (1997) The Squandered Computer; Evaluating the Business Alignment of Information Technologies. Information Economics Press, New Canaan, Connecticut. 
Van der Zee, H. (2002) Measuring the Value of Information Technology. Idea Publishing Group, Hershey

Weill, P. The relationship between investment in information technology and form performance: a study of the valve manufacturing sector. Information Systems Research, 3(4): 307-333.

Willcocks, L.P. and Lester, S. (1999) Information technology: transformer or sink hole? In Willcocks, L.P. and Lester, S. (eds.) Beyond the IT Productivity Paradox. Wiley, Chichester.

\section{COPYRIGHT}

Peter Marshall, Judy McKay and Adi Prananto (C) 2004. The authors assign to ACIS and educational and non-profit institutions a non-exclusive licence to use this document for personal use and in courses of instruction provided that the article is used in full and this copyright statement is reproduced. The authors also grant a non-exclusive licence to ACIS to publish this document in full in the Conference Papers and Proceedings. Those documents may be published on the World Wide Web, CD-ROM, in printed form, and on mirror sites on the World Wide Web. Any other usage is prohibited without the express permission of the authors. 